\title{
Making the grade: supporting mathematics students in understanding the use of grade-based marking criteria for assessments
}

Ewan Russell, Department of Mathematical Sciences, University of Liverpool, Liverpool, UK. Email: Ewan.Russell@liverpool.ac.uk

\begin{abstract}
Grade-based marking criteria are used widely in humanities subjects, and also in some areas of the sciences. In many mathematics assessments, individual marks are clearly allocated for specific elements of working in calculations, computations or theoretical arguments. This case study will document the use of grade-based marking criteria for assessments in a final year mathematics module at a mainstream UK university. The module has the development of professional skills for mathematics as the central focus and the assessment tasks take the form of written reports and oral presentations. This paper will describe formative group tasks set in the initials weeks of the module to introduce students to the grade-based marking criteria, and to provide students with experience of using the criteria themselves. The success of these initiatives in developing student appreciation for the use of the assessment criteria will be discussed, along with ideas for the future based on student responses to the activities.
\end{abstract}

Keywords: Assessment, marking criteria, peer learning, group exercises, project work.

\section{Introduction and background}

Employability has been a key priority for universities over the past five years, with the contribution of student outcomes and graduate destinations three years after graduation now feeding directly into the next Teaching Excellence and Student Outcomes Framework (TEF) exercise (Office for Students, 2018). Universities have been keen to emphasise to students the importance of careers awareness and the need for students to develop and successfully articulate employability skills during their degree programmes.

The university in this case study introduced an institution-wide agenda focused on employability in 2012. Individual departments were instructed to introduce appropriate learning opportunities within undergraduate programmes for students to develop their employability skills. The Mathematics department established a skills strand of modules, with one skills module available to students in each academic year. These modules embed skills development and offer opportunities to interact with representatives from industry within credit-bearing taught mathematics modules rather than offering these activities in stand-alone sessions. It is recognised that stand-alone sessions are not generally as successful in engaging students as embedded sessions, and that students can place more value in advice from industrial representatives than academic or careers staff (Cranmer, 2006; Chadwick et al., 2011).

Each of the modules in the strand requires students to tackle unstructured problems and work in groups on extended mathematical investigations. The modules also require students to reflect on skills development as part of the module assessment. This is seen as a crucial part of employability training as individuals are able to articulate and evidence skills development clearer, and make appropriate plans for future development through sustained emphasis on reflection (Pegg et al., 2012). 
This paper will consider the final year module in the strand, which has a specific focus on professional skills development. This final year optional module aims to simulate many aspects of working for a mathematical consultancy and requires students to work in groups on genuine problems faced by industry and business. The outputs in this module must be tailored to client audiences where there can often be no assumption that the audience has high-level knowledge of mathematics (i.e. beyond college level). The challenge in this module is for students to successfully communicate the results of extended mathematical investigations to these particular audiences, in both written and oral reports.

The final year module in the strand has been running since the $2012 / 13$ academic year. The module is a 15-credit module which is available to both Single Honours and Combined Honours students. On average, fifty students select the module each year. The module is taught in a computer lab setting and the timetabled activity for the module is one three-hour lab session per week. The aim of this teaching structure is to allow student groups to spend extended time on the group projects.

\section{Grade-based assessment criteria}

The university in this study has a set of grade-based assessment criteria used across the institution. Examples of the criteria can be found in Table 1. The use of a standard set of grade-based assessment criteria across the university provides a common currency across different disciplines, which percentage scales don't always provide and can help to limit discrepancy with markers' individual judgements.

Table1: Examples of the university grade-based assessment criteria.

\begin{tabular}{|c|c|c|}
\hline UG Award & Example Descriptors & Possible Outcomes (\%) \\
\hline First & $\begin{array}{ll}\text { - } & \text { Knowledge of a } \\
\text { sufficient number of } \\
\text { core materials } \\
\text { - } & \text { Arguments are well } \\
\text { constructed but do not } \\
\text { develop sufficiently } \\
\text { some significant issues } \\
\text { - Clear style with } \\
\text { satisfactory } \\
\text { presentation }\end{array}$ & $100,90,80,75,72$ \\
\hline Upper Second & $\begin{array}{l}\text { - Some knowledge of a } \\
\text { restricted range of } \\
\text { issues relevant to the } \\
\text { assessment } \\
\text { - Some development or } \\
\text { illustration of points } \\
\text { - Arguments are poorly } \\
\text { constructed with weak } \\
\text { / simplistic } \\
\text { presentation }\end{array}$ & $68,65,62$ \\
\hline Lower Second & $\begin{array}{l}\text { Knowledge of a } \\
\text { sufficient number of } \\
\text { core materials }\end{array}$ & $58,55,52$ \\
\hline
\end{tabular}




\begin{tabular}{|c|c|c|}
\hline & $\begin{array}{l}\text { - Arguments are well } \\
\text { constructed but do not } \\
\text { develop sufficiently } \\
\text { some significant issues } \\
\text { - Clear style with } \\
\text { satisfactory } \\
\text { presentation }\end{array}$ & \\
\hline Third & $\begin{array}{l}\text { - Some knowledge of a } \\
\text { restricted range of } \\
\text { issues relevant to the } \\
\text { assessment } \\
\text { - Some development or } \\
\text { illustration of points } \\
\text { - Arguments are poorly } \\
\text { constructed with weak } \\
\text { / simplistic } \\
\text { presentation }\end{array}$ & $48,45,42$ \\
\hline
\end{tabular}

Careful consideration is advised when applying assessment criteria to student work in general. The main points are summarised by Sadler (2005) who observes that criteria for assessed work should be clearly explained to students at the beginning of a course. In particular, "students deserve to know the criteria by which judgements will be made about the quality of their work" (p.127).

Sadler also advises that there should be clear communication of standards across a community of learners which should cover qualifying thresholds and agreeing standards. Sadler concludes that a major barrier to success when using grading criteria is that the key decisions are made in contexts where students do not normally have access to the standards which are applied, or the judgemental process of the assessor.

Several authors offer advice on avoiding the pitfalls highlighted by Sadler when applying assessment criteria to student work. Andrews et al. (2018) advocate bringing students into the conversation where marking criteria is concerned. Robinson (2015) notes that in-class exercises and informal discussions between students can help to understand marking and the associated feedback. On the theme of feedback, Schinske and Tanner (2014) argue that more time to should be allocated to self and peer evaluation and reflection in an active learning environment.

A major concern in the use of grade-based assessment criteria for the module in this study is that mathematics students have little experience of being formally assessed on report writing. Marking schemes are regularly provided in mathematics modules which account for each individual mark. This enables students to identify precisely where any marks were lost. The qualitative nature of marking to a grade-based set of assessment criteria is something which mathematics students need a formal introduction to. Subsequent advice and support in adapting to the use of such criteria is also needed.

\section{Initiatives in the $2017 / 18$ academic year}

To support students in making sense of and using the grade-based assessment criteria, several initiatives were introduced in the 2017/18 academic year. These included class discussions on report writing, specifically the need to be aware of the audience or reader for a particular piece of written work. In this case, the differences in style required for client reports and more technical / mathematical reports was discussed in detail. The evolution of the criteria in line with the module aims was also explored as part of this initial set of class discussions. In addition to these class-wide 
discussions, a formative group exercise on applying the criteria to sample reports was set in the subsequent lab session.

For the group exercise, a sample project brief and three sample reports were provided to students via the Virtual Learning Environment. The sample brief was for a client-based project where the main output required was a client report written in a style appropriate for the given client. Students were asked to read through the brief and the sample reports. Each group was then asked to write down their initial thoughts on each report and responses were collected anonymously on an online form. This initial thought gathering was not intended to be formally linked to the assessment criteria at this stage, but was to collect first impressions.

The second stage in the group exercise was for the groups to formalise their critique of the sample reports by writing down a mark and formal feedback on each report, aligned with the marking criteria. This again was collected on an online form. For this activity, the groups were selected by the students themselves. Sixteen groups, each consisting of 3-5 members were formed. The activity took place in the second week of the module. This week was selected for the activity as this was before any assessed work was to be submitted and could therefore align with suggestions from Sadler that students must be clearly introduced to the methods by which they will be assessed before any formal assessment takes place.

Students were informed that the intention of the exercise was to familiarise themselves with the way in which work is assessed in the module using the assessment criteria, and how initial impressions on reading through a piece of work must then be justified and considered against the formal criteria. This approach aligns with the suggestions of Robinson (2015) and Schinske and Tanner (2014).

\section{Results and analysis from the group exercise}

Sixteen responses were received. Each of the sixteen student groups proposed a mark and provided initial thoughts and formalised feedback on the three sample reports. The sample reports had been marked by the lecturer separately (prior to the group exercise) and a comparison of the classifications, along with the main student comments on the reports can be found in Table 2. A group comment was classed as a 'popular' comment if it was mentioned in the feedback from four or more groups in the exercise. An open class discussion was held to cover the results of the exercise and to clarify any confusion or concerns about the use of the criteria.

Table 2: Results from group exercise on applying the marking criteria.

\begin{tabular}{|c|c|c|c|}
\hline & Sample Report 1 & Sample Report 2 & Sample Report 3 \\
\hline $\begin{array}{l}\text { Mean student group } \\
\text { mark }\end{array}$ & Upper Second Class & Third Class & Upper Second Class \\
\hline $\begin{array}{l}\text { Lecturer } \\
\text { classification }\end{array}$ & First Class & Third Class & Upper Second Class \\
\hline $\begin{array}{l}\text { Popular student } \\
\text { comments }\end{array}$ & $\begin{array}{l}\text { - Shows } \\
\text { awareness of } \\
\text { the client's } \\
\text { needs } \\
\text { - } \text { Robust } \\
\text { arguments }\end{array}$ & $\begin{array}{ll}- & \text { Presentation is } \\
\text { poor overall } \\
\text { - } & \text { Lack of structure } \\
\text { and difficult to } \\
\text { navigate } \\
\text { - } \\
\text { fraphs and } \\
\text { figures are all }\end{array}$ & $\begin{array}{ll}\text { - } & \text { Good overall } \\
\text { presentation } \\
\text { - } & \text { Suitable } \\
& \text { sections } \\
\text { - } & \text { Evidence of } \\
& \text { original } \\
\text { thought }\end{array}$ \\
\hline
\end{tabular}




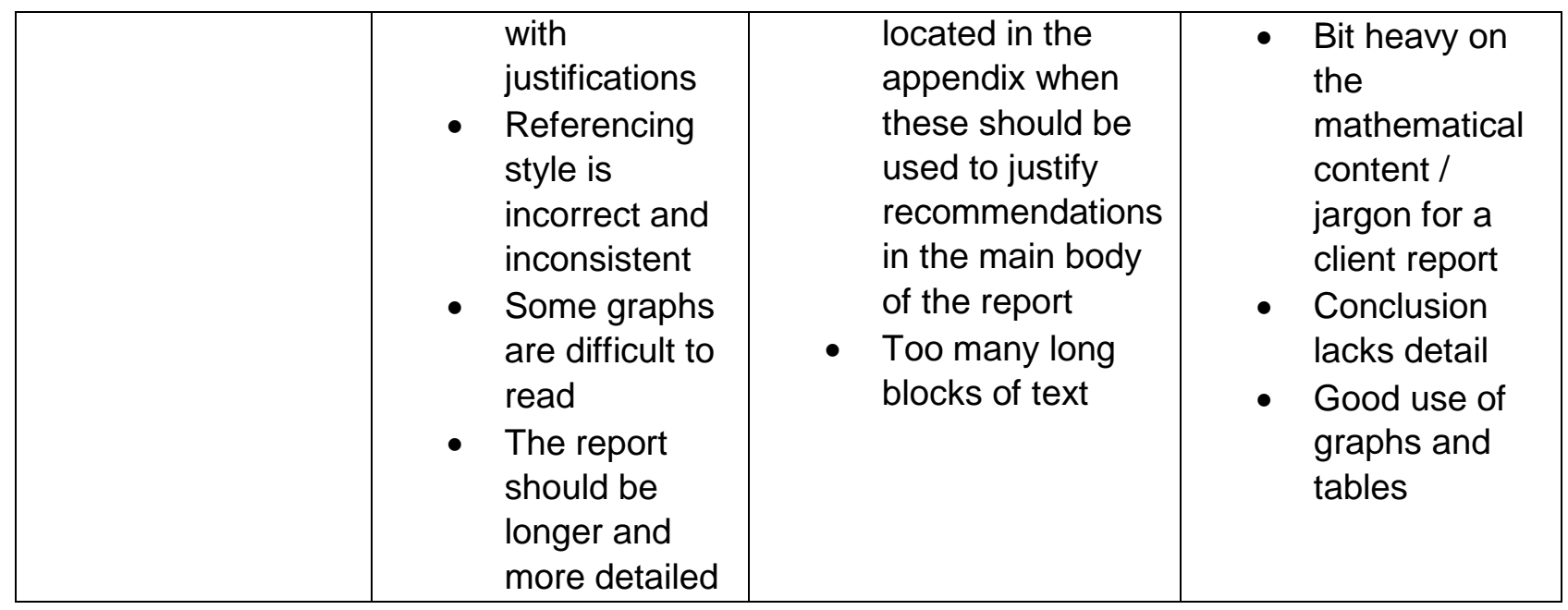

Most of the points raised by the student groups in their feedback on the sample reports are relevant and are emphasised in the descriptions of the marking criteria. The lecturer awarded sample report 1 a First Class mark but the student groups classified this report as Upper Second Class standard. When this was discussed with students, it was acknowledged that the point raised by the groups on the length of this report was perhaps not entirely valid for this report brief. The class agreed that a longer report does not always indicate a better report. In this circumstance, the report was for a client reader and students were reminded about their briefing on report writing, specifically that lengthy mathematical calculations are not really appropriate for this type of report. Students were also reminded that client reports require the author to be more concise and to-the-point than formal mathematical research reports. The style guidelines for client reports were also highlighted again. In particular, the use of summaries and appropriate sub-sections was recommended to help with the readability of the report.

There was consensus that sample report 2 had very poor structure and layout. The class discussion was used to emphasise the importance of presentation and the organisation of mathematical results in a client report. Some students queried whether sample report 2 should be classified as a Fail. The class examined the marking criteria again and observed that the report aligned with the Third Class classification, but possibly the lower end of the mark scale.

Sample report 3 was widely appreciated for the many positive aspects of its layout and content. Evidence of original thought was highlighted but the student comments which were submitted acknowledged that the report was not written in a style which was suitable for the client reader. This was encouraging as it indicated that students were possibly developing an awareness of the structure and content which is suitable in a client report.

In this exercise there was a clear difference in the language used by student groups when articulating 'initial thoughts' and 'formal feedback'. The formal feedback comments regularly made use of the formal marking criteria descriptions while the initial thoughts were brief, at times informal, comments such as "too long", "too many tables", "mostly a solid report, some grammar errors", or "easy to follow".

There was a tendency in the formal feedback for student groups to list many negative points about the given report without highlighting any positive features. This was discussed with the class as a whole and students recognised the importance of fixing the grade based on a clear link with the descriptors, stating features which are present in the work, while also identifying features from higher band descriptors which can be included next time as useful feed-forward actions. 


\section{Impact of the initiatives and future plans}

Following the exercises in the first few weeks of the module, the lecturer took time to discuss the results and formal feedback from the first assessed report with each group individually. These discussions indicated that the groups understood their marks and saw how these were aligned with the assessment criteria. This first assessed report was on a project with significant time pressure and several groups acknowledged that the communication and presentation of their results had suffered. These groups admitted that the project planning stages had not allocated sufficient time to the development of the report and the communication of the mathematical results. Some groups were able to identify criticisms within their own feedback from the lecturer which they had previously highlighted themselves in the exercise on grading sample reports. These groups were frustrated by this fact, but the realisation seemed to enhance their determination to put actions in place for subsequent projects. In particular, the experience here seemed to lead to a greater appreciation of the project process as a whole rather than just the final report as an isolated element.

Each group was also able to see how the feedback could be channelled into successful feed-forward actions for the next project. This is encouraging and indicates that some students are able to see the process of receiving feedback as purposeful and motivational. The documented dangers of grading playing on students' fears or desires to outcompete peers (Schinske and Tanner, 2014) do not appear to be manifesting in this module. Instead, students are engaging in meaningful reflection and demonstrating enhanced appreciation for the clarity of the grade descriptors.

In previous years, there were occasionally a couple of student comments in end-of-module feedback forms raising some dissatisfaction with the clarity of the marking process when compared with other mathematics modules. The introduction of the initiatives and group exercises in the 2017/18 academic year resulted in the positive developments outlined above and also the absence of any comments in end-of-module feedback forms concerning the use of the grade-based assessment criteria. Student opinions and experiences of the marking process in the module should be explored further as the end-of-module feedback form does not specifically ask for feedback on the grading of assessments or the use of relevant criteria. A specific question on this could be included in future.

Future work could formalise this process of reflection on group projects and the documentation of feed-forward actions based on this. It could also be interesting to consider the use of anonymous peer marking to provide students with further experience of using the marking criteria themselves in practice. The process of reading the work of others could prompt groups to make improvements in their own work based on features identified in the work of their peers. Again, it would be interesting to document this somehow, possibly in the form of reflections after the peer marking exercise.

\section{References}

Andrews, M., Brown, R, and Mesher, L., 2018. Engaging students with assessment and feedback: improving satisfaction with students as co-designers. Practitioner Research in Higher Education, Vol. 11, No. 1, pp.32-46. Available at:

http://insight.cumbria.ac.uk/id/eprint/3840/1/Andrews EngagingStudents.pdf [Accessed 11 March 2019].

Chadwick, E., Sandicroft, K., and Percy, D., 2011. Assessing student teams developing mathematical models applied to business and industrial mathematics. MSOR Connections, 11(3), pp.22-24.

Cranmer, S., 2006. Enhancing graduate employability: Best intentions and mixed outcomes. Studies in Higher Education, 31(2), pp.169-184. https://doi.org/10.1080/03075070600572041. 
Office for Students, 2018. Teaching Excellence and Student Outcomes Framework Year Four Procedural Guidance. Available at: https://www.officeforstudents.org.uk/media/da96d15a-97e64732-a2f5-cb2473633932/ofs2018 45.pdf [Accessed 11 March 2019].

Pegg, A., Waldock, J., Hendy-Isaac, S., and Lawton, R., 2012. Pedagogy for employability. Higher Education Academy.

Robinson, M., 2015. Providing effective feedback. In: Grove, M. et al., [eds.] Transitions in Undergraduate Mathematics Education, University of Birmingham, pp.159-172.

Sadler, D.R., 2005. Interpretations of criteria-based assessment and grading in higher education. Assessment and Evaluation in Higher Education, Vol. 30, No. 2, pp.175-194. https://doi.org/10.1080/0260293042000264262.

Schinske, J., and Tanner, K., 2014. Teaching More by Grading Less (or Differently). CBE Life Sciences Education, 13(2), pp.159-166. https://doi.org/10.1187/cbe.CBE-14-03-0054. 